\title{
Comparison of cognitive profiles in spinocerebellar ataxia subtypes: a case series
}

\author{
Corey Bolton ${ }^{*}$ (1) and Maureen Lacy
}

\begin{abstract}
Background: The spinocerebellar ataxias (SCA) are a heterogeneous group of progressive neurodegenerative disorders that are associated with diffuse cerebellar atrophy. While the physical symptoms of this condition have long been studied, more attention has been given to cognitive changes in recent years. We describe a case series of four adults with various genetically-confirmed subtypes of SCA.

Case presentation: Patients with SCA types 2, 3, and 6 presented with impaired cognitive profiles consistent with the existing literature while the reported patient with SCA-14 showed notable impairment inconsistent with the only published case controlled study.

Conclusions: Comparisons were made between the four patients with a common pattern of slowed processing speed, poor memory retrieval, and reduced mental flexibility. Confrontation naming and consolidation-based memory were intact across all patients. These findings are discussed in light of the relevant literature on cerebellar cognitive affective syndrome.
\end{abstract}

Keywords: Cerebellum, Spinocerebellar ataxias, Neuropsychology, Cognition, Depression

\section{Background}

The spinocerebellar ataxias (SCA) are a group of progressive neurodegenerative disorders marked by ataxia and a variety of other neurologic features with atrophy predominantly in the cerebellum. There is significant heterogeneity between the unique subtypes with regard to the pattern of neurodegeneration and subsequent clinical features. There has been much recent interest in the nonmotor functions of the cerebellum, stemming primarily from the proposed cerebellar cognitive affective syndrome (CCAS [1];). SCAs, with their notable cerebellar involvement, typically are associated with cognitive deficits; however, there is little understanding as to typical neurocognitive profiles associated with each subtype. Disruption of cerebrocerebellar circuitry has been posited as a mediator of the relationship between SCA and cognitive impairment, though given the heterogeneity of pathology in SCA, some differences in neurocognitive functioning have been noted across the various

\footnotetext{
* Correspondence: corey.bolton@my.wheaton.edu

Department of Psychiatry and Behavioral Neurosciences, University of

Chicago Medical Center, 5841 S. Maryland Ave, Chicago, IL 60637, USA
}

subtypes [2]. Cognitive impairment in SCA seems to correlate with the severity of physical symptoms, suggesting that the extent of cerebellar dysfunction is directly related to neurocognitive functioning [3]. The following cases highlight key differences in neurocognitive presentation between four different genetically-confirmed subtypes of SCA. Table 1 lists neuropsychological measures used and summarizes neurocognitive profiles for each patient. Standardized scores were obtained from commonly used normative data with corrections for age and, as available, other demographic variables such as education, gender, and ethnicity.

\section{Case presentation}

Case 1 - SCA2

A 66-year-old African-American female with 14 years of education presented with slowly progressive imbalance, dysarthria, and dysmetria over the last 40 years. More recently she began to note mild memory problems. Neurological exam was notable for wide-based, ataxic gait, mild dysarthria, slowed eye movements, and abnormal finger-nose-finger and alternating movements. The Scale 
Table 1 Summary of neuropsychological assessment data by subtype of SCA

\begin{tabular}{|c|c|c|c|c|c|c|}
\hline & & & Case 1 & Case 2 & Case 3 & Case 4 \\
\hline SCA Subtype & & & 2 & 3 & 6 & 14 \\
\hline Age (years) & & & 66 & 53 & 70 & 46 \\
\hline Disease Duration (years) & & & 40 & 12 & 25 & 3 \\
\hline SARA Score & & & 9 & 21 & 18.5 & 11 \\
\hline Global & MMSE [4] & & - & - & - & - \\
\hline \multirow[t]{6}{*}{ Verbal Memory } & \multirow[t]{3}{*}{ Verbal List (RBANS or CVLT-II) $[5,6]$} & Immediate Recall & +++ & + & ++ & - \\
\hline & & Delayed Recall & ++ & - & ++ & - \\
\hline & & Recognition & +++ & - & - & + \\
\hline & \multirow[t]{3}{*}{ Verbal Story (RBANS or WMS-IV) $[5,7]$} & Immediate Recall & ++ & - & - & - \\
\hline & & Delayed Recall & ++ & - & - & - \\
\hline & & Recognition & +++ & - & - & - \\
\hline \multirow[t]{6}{*}{ Visual Memory } & \multirow[t]{3}{*}{ Simple (BVMT-R) [8] } & Immediate Recall & - & ++ & + & ++ \\
\hline & & Delayed Recall & - & ++ & - & ++ \\
\hline & & Recognition & - & - & + & + \\
\hline & \multirow[t]{3}{*}{ Complex (RCFT) [9] } & Immediate Recall & / & - & / & ++ \\
\hline & & Delayed Recall & / & - & / & ++ \\
\hline & & Recognition & / & - & / & ++ \\
\hline \multirow[t]{2}{*}{ Visuospatial } & Line Orientation (RBANS or JLO) $[5,10]$ & & - & - & - & - \\
\hline & Clock Copy [11] & & - & + & - & - \\
\hline \multirow[t]{3}{*}{ Language } & Boston Naming Test [12] & & - & - & - & - \\
\hline & Verbal Fluency [13] & Phonemic & - & +++ & - & ++ \\
\hline & & Semantic & + & ++ & ++ & - \\
\hline \multirow{6}{*}{$\begin{array}{l}\text { Executive Functions } \\
\text { Attention and } \\
\text { Processing Speed }\end{array}$} & \multirow[t]{3}{*}{ WCST [14] } & Errors & - & - & - & + \\
\hline & & Perseverative Responses & + & + & - & - \\
\hline & & Categories Completed & + & - & + & + \\
\hline & Trail Making Test Part B [15] & & ++ & ++ & + & + \\
\hline & Trail Making Test Part A [15] & & ++ & + & + & + \\
\hline & Symbol-Digit Coding (RBANS or SDMT) $[5,16]$ & & + & ++ & + & + \\
\hline Depression & Screening Measure (BDI-II or GDS) $[17,18]$ & & + & ++ & - & - \\
\hline
\end{tabular}

$+=$ Mildly Impaired, ++ = Moderately Impaired, +++ = Severely Impaired, - = Within Normal Limits, / = Not assessed. All comparisons are with normative data. SCA2 = spinocerebellar ataxia type 2, SCA3 = spinocerebellar ataxia type 3, SCA6 = spinocerebellar ataxia type 6, SCA14= spinocerebellar ataxia type 14. MMSE = Mini Mental State Examination; RBANS = Repeatable Battery for the Assessment of Neuropsychological Status; CVLT-II = California Verbal Learning Test - Second Edition; WMS-IV = Wechsler Memory Scale - Fourth Edition; BVMT-R = Brief Visuospatial Memory Test - Revised; RCFT = Rey Complex Figure Test; JLO = Judgement of Line Orientation; $W C S T=$ Wisconsin Card Sorting Test; SDMT = Symbol Digit Modalities Test; BDI-II = Beck Depression Inventory - Second Edition; GDS = Geriatric Depression Scale

for the Assessment and Rating of Ataxia (SARA) total score was 9. Neuropsychological assessment revealed grossly intact cognition on screening (Mini-Mental State Examination; MMSE $=27$ ) with more in-depth assessment revealing notable difficulties in verbal learning, processing speed, mental flexibility, speeded semantic fluency and problem solving deficits. Responses to a self-report measure also revealed mild acute clinical depressive symptoms. Visual memory, visuospatial and constructional abilities, confrontational naming, and phonemic fluency were as expected for age and education.

\section{Case 2 - SCA3}

A 53-year-old Caucasian male with 12 years of education presented with a 12-year history of progressive imbalance, slurred speech, and hand incoordination with no reported cognitive difficulties. Additionally, he reported urinary incontinence, diplopia, and dysarthria. He began using a walker 7 years ago and now requires a wheelchair. Neurological exam was notable for square wave jerks, moderate dysarthria, wide-based ataxic gait, abnormal finger-nose-finger with intention tremor, abnormal alternating movements, and absent reflexes in biceps, brachioradialis, knee jerks, and ankle jerks. Total SARA 
score was 21. Neuropsychological assessment revealed grossly intact cognition upon screening $(\mathrm{MMSE}=28)$ with further evaluation revealing deficits in memory retrieval for visual and verbal material, along with processing speed, mental flexibility, speeded semantic fluency, and speeded phonemic fluency deficits. On a self- report questionnaire, he endorsed symptoms indicative of a clinical depression in the moderate range of severity. Visuospatial perception, memory consolidation and object naming were within normal limits.

\section{Case 3 - SCA6}

A 70-year-old Caucasian female with 16 years of education presented with imbalance, dysarthria, and dyscoordination that has progressed over the last 25 years. Neurological exam revealed abnormal eye movements, mild to moderate dysarthria, intention tremor, abnormal alternating movements and finger-nose-finger, and widebased ataxic gait. The SARA total score was 18.5. Neuropsychological assessment revealed grossly intact cognition on screening $(\mathrm{MMSE}=27)$ with more in-depth assessment revealing difficulties in memory retrieval, processing speed, semantic fluency, and mental flexibility. Visuospatial perception, visuoconstructional abilities, object naming, and phonemic fluency were within normal limits, as were scores on a depression screener.

\section{Case 4 - SCA14}

A 46-year-old Caucasian male with 12 years of education presented with a 3 year history of progressive dysarthria, unsteady gait, vision problems, and cognitive deficits. He also reported a history of seizures and slow speech dating back to childhood. Neurological exam revealed abnormal eye movements, mild dysarthria, abnormal finger-nose-finger and heel-knee-shin, mild intention tremor, and ataxic gait. The SARA total score was 11 . Neuropsychological assessment revealed notable deficits in visual learning, processing speed, and speeded phonemic fluency. Performances in tests of verbal memory, semantic fluency, object naming, and visuoconstructional abilities were as expected for age and education. On a self-report questionnaire, the patient endorsed only minimal depressive symptoms.

\section{Discussion}

We describe a case series of adults with various genetically-confirmed subtypes of SCA. All cases presented with characteristic ataxic gait, ocular motor abnormalities, dysarthria, and uncoordinated movement upon neurological examination. Ataxia severity was variable with SARA scores ranging from 9 to 21. These symptoms are consistent with diffuse cerebellar atrophy. While it has long been recognized that the cerebellum serves a critical role in movement, nonmotor symptoms of cerebellar dysfunction have been increasingly realized in recent years.

Past studies have shown that SCA subtypes 2, 3, and 6 are often associated with a frontal-subcortical pattern of neurocognitive impairment. Primarily, deficits have been described in attentional abilities and executive functions $[2,3,19-26]$. The patients in this report with the more common SCA subtypes of 2, 3, and 6 presented with very similar neurocognitive profiles as previously described. SCA14, the rarest of the four presented subtypes, has received very little attention with regard to the associated cognitive profile. The one case controlled study that has been reported found very little neurocognitive impairment in these patients [27]. Our patient, however, displayed notable deficits in visual memory, processing speed, and speeded phonemic fluency. It is notable, however, that this patient had limited premorbid intellect and a history of childhood seizures, thus increasing vulnerability and making generalizable conclusions about the effects of SCA on his cognition difficult to obtain.

Comparison of the four patients in this case series highlights the distinct cognitive profiles associated with various subtypes of SCA, as supported by larger past studies [2, 3, 19-27]. While some heterogeneity exists, there were some notable commonalities as well. Across all patients, processing speed was notably slowed. This is consistent with recent findings of slowed processing speed in patients with reductions in gray matter in the posterior lobule of the cerebellum [28]. Additionally, all patients displayed learning or memory retrieval deficits, with no one exhibiting pure memory consolidation deficits. Verbal fluency was reduced for all patients, though the modality (phonemic vs. semantic) was inconsistent. Finally, all patients displayed mental flexibility impairment consistent with frontal circuity disruption.

The deficits observed in this small sample of SCA patients were consistent with the CCAS with deficits in executive functioning, memory retrieval and aspects of language abilities [29]. One notable difference amongst this sample is that no patients in the present study were found to have even a mild anomia. In the defining study of CCAS, 13 of 20 patients experienced difficulties with confrontation naming, though it was noted that naming was spared in those with smaller lesions [1]. It was suggested that naming deficits in CCAS may represent impaired lexical access, as patients appear to improve with phonemic cueing [30]. It is likely, therefore, that naming deficits may only be present in late stage SCA, once cerebellar-prefrontal networks have been sufficiently degraded to inhibit lexical access.

\section{Conclusions}

SCA is a progressive neurodegenerative disease that selectively targets the cerebellum. Given the recent exploration of the cerebellum's role in cognition, the neurocognitive 
profile of this disease is of interest. This study provided support for the growing literature of the neurocognitive profiles associated with SCA2, SCA3, and SCA6, while also providing the first report of a pattern of deficits in SCA14. Amongst all four subtypes, slowed processing speed was found. This likely reflects the important role of the cerebellum in efficient information processing. Further, it was noted that no patients were anomic, a finding contrary to that expected from the CCAS literature and likely indicative of less advanced disease.

\section{Abbreviations}

CCAS: cerebellar cognitive affective syndrome; MMSE: Mini-Mental State Examination; SARA: Scale for the Assessment and Rating of Ataxia;

SCA: spinocerebellar ataxia

\section{Acknowledgements}

Not applicable.

\section{Authors' contributions}

All authors were involved in the conception and design of the work, the acquisition, analysis, and interpretation of data. CB drafted the manuscript with revisions and recommendations from ML. Both authors read and approved the final manuscript.

\section{Funding}

This research was not supported by any funding source.

\section{Availability of data and materials}

All data generated or analyzed during this study are included in this published article in Table 1. Raw data scores are available from the corresponding author upon request.

\section{Ethics approval and consent to participate}

This study was approved by the University of Chicago Medicine Institutional Review Board.

\section{Consent for publication}

Not applicable.

\section{Competing interests}

The authors declare that they have no conflict of interest.

Received: 25 April 2019 Accepted: 11 September 2019

Published online: 18 September 2019

\section{References}

1. Schmahmann JD, Sherman JC. The cerebellar cognitive affective syndrome. Brain J Neurol. 1998;121 ( Pt 4:561-79.

2. Bürk K, Globas C, Bösch S, Klockgether T, Zühlke C, Daum I, et al. Cognitive deficits in spinocerebellar ataxia type 1, 2, and 3. J Neurol. 2003; 250(2):207-113.a.

3. Ma J, Wu C, Lei J, Zhang X. Cognitive impairments in patients with spinocerebellar ataxia types 1,2 and 3 are positively correlated to the clinical severity of ataxia symptoms. Int J Clin Exp Med. 2014;7(12):5765-71.

4. Folstein MF, Folstein SE, McHugh PR. Mini-mental state examination: PsycTESTS.; 1975.

5. Randolph C. Repeatable battery for the assessment of neuropsychological status. PsycTESTS.; 1998.

6. Delis DC, Kramer JH, Kaplan E, Ober BA. California verbal learning test-second edition: PsycTESTS.; 1987.

7. Wechsler D. Wechsler memory scale--fourth edition; PsycTESTS, 2009.

8. Benedict RHB. Brief visuospatial memory test - revised: professional manual. Lutz, FL: Psychological Assessment Resources, Inc; 1997.

9. Rey A, Osterrieth PA. Rey-Osterrieth complex figure test; PsycTESTS, 1941.

10. Benton AL, Varney NR, deS HK. Judgment of line orientation. PsycTESTS; 1975.

11. Rouleau I, Salmon DP, Butters N, Kennedy C, McGuire K. Clock drawing test: Rouleau scale. PsycTESTS; 1992.
12. Kaplan E, Goodglass H, Weintraub S. Boston Naming Test PsycTESTS. 1983.

13. Benton AL, Hamsher de SK, Sivan AB. Controlled Oral Word Association Test PsyCTESTS. 1983

14. Grant DA, Berg EA. Wisconsin card sorting test: PsycTESTS.; 1948.

15. Armitage SG. Trail Making Test: PsycTESTS.; 1946.

16. Smith A. Symbol digit modalities test: PsycTESTS.; 1973.

17. Beck AT, Steer RA, Brown G. Beck depression inventory-II. PsycTESTS; 1996.

18. Yesavage JA, Brink TL, Rose TL, et al. Geriatric depression scale: PsycTESTS.; 1983.

19. Klinke I, Minnerop M, Schmitz-Hübsch T, Hendriks M, Klockgether T, Wüllner $U$, et al. Neuropsychological features of patients with spinocerebellar ataxia (SCA) types 1, 2, 3, and 6. Cerebellum Lond Engl. 2010;9(3):433-42.

20. Moriarty A, Cook A, Hunt H, Adams ME, Cipolotti L, Giunti P. A longitudinal investigation into cognition and disease progression in spinocerebellar ataxia types 1, 2, 3, 6, and 7. Orphanet J Rare Dis. 2016;11(1):82.

21. Kawai $Y$, Suenaga $M$, Watanabe $H$, Sobue $G$. Cognitive impairment in spinocerebellar degeneration. Eur Neurol. 2009;61(5):257-68.

22. Cooper FE, Grube M, Elsegood KJ, Welch JL, Kelly TP, Chinnery PF, et al. The contribution of the cerebellum to cognition in spinocerebellar Ataxia type 6. Behav Neurol. 2010;23(1-2):3-15.

23. Rentiya ZS, Jung BC, Bae J, Liszewski CM, Fishman A, Du AX, et al. Selective patterns of cognitive impairment in spinocerebellar Ataxia type 6 and idiopathic late-onset cerebellar Ataxia. Arch Clin Neuropsychol Off J Natl Acad Neuropsychol. 2018;33(4):427-36.

24. Suenaga M, Kawai Y, Watanabe H, Atsuta N, Ito M, Tanaka F, et al. Cognitive impairment in spinocerebellar ataxia type 6. J Neurol Neurosurg Psychiatry. 2008:79(5):496-9.

25. Tamura I, Takei A, Hamada S, Nonaka M, Kurosaki Y, Moriwaka F. Cognitive dysfunction in patients with spinocerebellar ataxia type 6. J Neurol. 2017; 264(2):260-7.

26. van Gaalen J, de Swart BJM, Oostveen J, Knuijt S, van de Warrenburg BPC, Kremer BHPH. Language impairment in cerebellar ataxia. Mov Disord Off J Mov Disord Soc. 2014 Sep;29(10):1307-12.

27. Wedding IM, Koht J, Dietrichs E, Landrø NI, Tallaksen CM. Cognition is only minimally impaired in spinocerebellar ataxia type 14 (SCA14): a neuropsychological study of ten Norwegian subjects compared to intrafamilial controls and population norm. BMC Neurol. 2013;13(1):186.

28. Moroso A, Ruet A, Lamargue-Hamel $D$, Munsch F, Deloire M, Coupé $P$, et al. Posterior lobules of the cerebellum and information processing speed at various stages of multiple sclerosis. J Neurol Neurosurg Psychiatry. 2017; 88(2):146-51.

29. Schmahmann JD. The cerebellum and cognition. Neurosci Lett. 2018.

30. Levisohn L, Cronin-Golomb A, Schmahmann JD. Neuropsychological consequences of cerebellar tumour resection in children: cerebellar cognitive affective syndrome in a paediatric population. Brain. 2000;123(5):1041-50.

\section{Publisher's Note}

Springer Nature remains neutral with regard to jurisdictional claims in published maps and institutional affiliations.

Ready to submit your research? Choose BMC and benefit from:

- fast, convenient online submission

- thorough peer review by experienced researchers in your field

- rapid publication on acceptance

- support for research data, including large and complex data types

- gold Open Access which fosters wider collaboration and increased citations

- maximum visibility for your research: over $100 \mathrm{M}$ website views per year

At $\mathrm{BMC}$, research is always in progress.

Learn more biomedcentral.com/submissions 